\title{
Influencing mechanism of energy-related carbon emissions in Xinjiang based on the input-output and structural decomposition analysis
}

\author{
WANG Changjian ${ }^{1}$, WANG Fei ${ }^{2}$, ZHANG Xiaolei ${ }^{3}$, ZHANG Hongou ${ }^{1}$ \\ 1. Guangzhou Institute of Geography, Guangdong Open Laboratory of Geospatial Information Technology and \\ Application, Guangzhou 510070, China; \\ 2. College of Geography Science and Tourism, Xinjiang Normal University, Urumqi 830054, China; \\ 3. Xinjiang Institute of Ecology and Geography, CAS, Urumqi 830011, China
}

\begin{abstract}
Analysis of carbon emission mechanism based on regional perspectives is an important research method capable of achieving energy savings and emission reductions. Xinjiang, an important Chinese energy production base, is currently going through a period of strategic opportunities for rapid development. Ensuring stable socio-economic development while achieving energy savings and meeting emission reductions targets, is the key issue currently facing the region. This paper is based on the input-output theory, and conducts a structural decomposition analysis on the factors affecting energy-related carbon emissions in Xinjiang from 1997 to 2007; this analysis employs a hybrid input-output analysis framework of "energy - economy - carbon emissions". (1) Xinjiang's carbon emissions from energy consumption increased from 20.70 million tons in 1997 to 40.34 million tons in 2007; carbon emissions growth was mainly concentrated in the production and processing of energy resources, the mining of mineral resources, and the processing industry. (2) The analysis of the direct effects of the influencing factors on carbon emissions showed that the change in per capita GDP, the final demand structure, the population scale, and the production structure were the important factors causing an increase in carbon emissions, while the decrease in carbon emission intensity during this period was the important influencing factor in stopping the growth of carbon emissions. This showed that while the sizes of Xinjiang's economy and population were growing, the economic structure had not been effectively optimized and the production technology had not been efficiently improved, resulting in a rapid growth of carbon emissions from energy consumption. (3) The analysis of the indirect effects of the influencing factors of carbon emission showed that the inter-provincial export, fixed capital formation, and the consumption by urban residents had significant influence on the changes in carbon emissions from energy consumption in Xinjiang. (4) The growth of investments in fixed assets of carbon intensive industry sectors, in addition to the growth of inter-provincial exports of
\end{abstract}

Received: 2016-07-29 Accepted: 2016-10-21

Foundation: National Natural Science Foundation of China, No.41501144; National Key Research and Development Program, No.2016YFA0602801; Guangdong Academy of Sciences Youth Science Foundation, No.qnjj201501; High-level Leading Talent Introduction Program of GDAS, No.2016GDASRC-0101; Scientific Platform and Innovation Capability Construction Program of GDAS, No.2016GDASPT-0210.

Author: Wang Changjian, PhD, specialized in energy geography. E-mail: wwwangcj@126.com 
energy resource products, makes the transfer effect of inter-provincial "embodied carbon" very significant.

Keywords: carbon emissions; input output-structural decomposition analysis; influencing factors; Xinjiang

\section{Introduction}

The international community has reached a consensus on the transition to a low-carbon economy, as climate change issues, characterized by global warming, have continued to attract widespread attention (Aldy and Stavins, 2012; Liu Weidong et al., 2016; Peters et al., 2013; Shen and Sun, 2016). China has become one of the world's largest energy consumers and leading emitters of greenhouse gases (GHGs) (Feng et al., 2013; Wang et al., 2014b). The carbon emissions problem now receives extensive and continued attention from policy makers, industrial manufacturers, and researchers, due to the pressure from international climate negotiations. The need for energy conservation and emissions reductions due to the constraints in domestic resources and the environment is also effective in drawing attention to the carbon emissions problem (Cyranoski, 2007; Piao et al., 2010; Qiu, 2008, 2009, 2011; Streets et al., 2001; Zeng et al., 2008). Hence, the government of China is committed, as declared at the 2009 Copenhagen Summit, to reduce the carbon dioxide intensity per unit Gross Domestic Product (GDP) in 2020 by $40 \%-45 \%$ from the 2005 levels, and to increase the fraction of energy consumption of non-fossil fuel energy resources to $15 \%$ (Qiu, 2009). The 12th Five-Year Plan (2011-2015) of China proposed that the consumption of non-fossil fuel energy resources should be $11.4 \%$ of the total primary energy consumption, thus the per unit GDP energy consumption and per unit carbon dioxide emission should be reduced by $16 \%$ and 17\%, respectively (Qiu, 2011). In 2013, the China State Council announced an energy consumption cap, equivalent to 4 billion tons of coal and in 2014, a United StatesChina joint announcement was made on climate change, with China pledging to achieve the carbon emissions reductions prior to 2030 (Malakoff, 2014). Therefore, in-depth studies on the factors influencing energy-related carbon emissions need to be performed, as the realization of a highly constraining carbon emissions reduction commitment while maintaining social stability and rapid economic development in the midst of China's economic growth, industrialization, and urbanization poses great challenges. Priority industries for energy conservation and carbon emissions reductions should be identified in a scientific manner, thus promoting harmonious energy, environment, and socio-economic development. This further highlights the importance and urgency of the research on energy-related carbon emissions.

Current research on energy-related carbon emissions largely comprise the following aspects: estimation and accounting of total carbon emissions (Akimoto et al., 2006; Gregg et al., 2008; Le Quéré et al., 2009), factors influencing carbon emissions and their mechanism of action (Cheng et al., 2014; Chuai et al., 2012; Liu Yansui et al., 2016; Wang et al., 2017; Wang et al., 2015; Wang et al., 2016), scenario analyses and forecast of carbon emissions (O'Neill et al., 2010; Tollefson, 2015; Williams et al., 2012), and carbon emission reduction technologies, and policy simulations (Chu and Majumdar, 2012; He et al., 2016; Jiang et al., 2010; Wang et al., 2014a; Wang et al., 2013). The key to the formulation of 
carbon emissions reduction policies and implementation of scenario simulations however, lies in the identification and analyses of the influencing factors and drivers of carbon emissions. Previous studies have shown that a multitude of factors have an effect on energy-related carbon emissions, the most predominant ones being the rapid increase in energy consumption and rapid socio-economic development. Al-mulali et al. used panel data to perform a study on 30 Sub-Saharan African countries and demonstrated that energy consumption has a strong driving effect on economic development and carbon emissions growth (Al-mulali and Sab, 2012). Similarly, Al-mulali also performed an empirical study on the factors influencing carbon emissions in 12 countries in the Middle East, and concluded that the energy consumption, Foreign Direct Investment (FDI), and GDP constitute the most important factors influencing carbon emissions (Al-mulali, 2012). Li et al. used the Path-STIRPAT model to investigate the factors affecting carbon emissions in China and concluded that per capita GDP growth formed the most predominant factor (Li et al., 2011). Zhu et al. applied an input-output model to study the energy-related residential carbon emissions in China from 1992 to 2005 and showed that the continuous increase in household energy consumption levels played a key role in the growth of direct household carbon emissions (Zhu et al., 2012). Moreover, low-carbon optimizations in energy resources and industrial structures helped slow down the growth of carbon emissions (Zhang, 2003, 2006; Zhang et al., 2005). By conducting a comparative study of the long-term growth of developed and developing countries, Zhang found that the diversified development of economic structures results in slowing down the increase of energy consumption demands (Zhang, 2003). Moreover, Zhang analyzed the effects of changes in the energy resource structure and the evolution of industrial structures on the increase of total carbon emissions and on the spatial patterns in China by establishing assessment models on the respective association of industry-energy and energy-carbon emissions (Zhang, 2006). Wu et al. adopted a DEA model to show that continuous improvements in energy efficiency in China were primarily driven by technological advances (Wu et al., 2012). Li et al. employed the STIRPAT model to analyze the empirical factors impacting energy-related carbon emissions at the provincial level in China and showed that in most provinces, technological advances led to a decline in carbon emissions (Li et al., 2012). With the continued globalization of world economy, the impacts of international and regional trade on carbon emissions have received continuous attention. Thus, in addition to the improvement in production technologies and energy use efficiency, developing countries, such as China, should also intensify research on embodied carbon emissions related to imports and exports (Du et al., 2011; Su et al., 2013). All the factors influencing carbon emissions can be summarized as population, economy, energy, industry, technology, and policy.

Previous research on energy-related carbon emissions focused mostly on macroscopic regional levels such as the global, continental, and national levels and relatively few studies have been carried out on smaller scales, i.e., the provincial and city levels. From a geographical perspective, the eastern, central, and western regions, as well as various provinces, cities, and autonomous regions of China have significant disparities in population growth, household consumption, socio-economic development, energy resources endowments, and technological levels (Feng et al., 2013). Moreover, previous studies on mechanisms impact- 
ing energy-related carbon emissions largely relied on econometric models to investigate the direct effects of various factors of carbon emissions other than the indirect effects from the perspective of the final demand level. Domestic research that analyzes the factors impacting carbon emissions at the provincial and city levels has only recently begun emerging. This is highly significant in that the multi-factor mechanisms impacting carbon emissions that were previously obscured by regional differences can now be studied. These local studies will provide useful guidelines for the formulation of more targeted and workable regional policies for reducing carbon emissions (Geng et al., 2013; Liang and Zhang, 2011; Liu Zhu et al., 2012; Wang et al., 2014c; Wang et al., 2014; Wang et al., 2013; Xi et al., 2011). Liu et al. used an index decomposition analysis (IDA) to perform a comparative study on the factors affecting carbon emissions from 1995 to 2009 in four municipalities including Beijing, Shanghai, Tianjin, and Chongqing (Liu Zhu et al., 2012). Wang et al. used the LMDI model to perform a decomposition analysis of the factors affecting energy-related carbon emissions in Shandong Province from 1990 to 2009 and concluded that economic growth and population size were the most crucial factors of carbon emissions growth (Wang et al., 2014c). Wang et al. applied the STIRPAT model to analyze the factors of carbon emissions in Guangdong from 1980 to 2010 and found that the population size, level of urbanization, per capita GDP, and the level of industrialization to be the key factors (Wang et al., 2013). Wang et al. adopted the IDA model to analyze energy-related carbon emissions in Suzhou from 2005 to 2010 and demonstrated that the reduction in energy consumption intensity attributed to the energy resources and industrial restructuring proved conducive to the containment of growth in carbon emissions (Wang et al., 2014). The research of Xi et al. in Shenyang City revealed that the key sectors that should be targeted for carbon emissions reductions are the energy generation and processing industry, manufacturing industry, and construction industry (Xi et al., 2011). Liang et al. took the structural decomposition analysis (SDA) to perform a decomposition analysis of the factors impacting carbon emissions in the Eastern Coastal Manufacturing Center in Jiangsu Province. The study found that while reductions in energy consumption intensity and optimization of energy consumption structures were important, embodied carbon emissions from international trade should also be targeted for carbon emissions reductions in order to achieve low-carbon development in Jiangsu Province (Liang and Zhang, 2011). Geng et al. found that interprovincial trade outflow has a significant effect on the growth of carbon emissions, based on a decomposition analysis of factors impacting carbon emissions in the old industrial bases of Liaoning Province in Northeast China (Geng et al., 2013). Therefore, a thorough and wide-ranging study on the factors impacting carbon emissions at the provincial and city levels is urgently required to enable provincial contributions to the fulfillment of carbon emissions reduction pledges at the national level. Xinjiang is one of the major integrated energy bases of China and an important gateway for development in the western regions of China, as well as the core region of the Silk Road Economic Belt. Xinjiang is currently experiencing a strategic period of leapfrogging development; the fulfillment of constraining energy and carbon emissions reduction targets in an effective manner while maintaining stable socio-economic growth will be decisive for the harmonious energy, environment, and socio-economic development in Xinjiang. 


\section{Study area}

The Xinjiang Uygur Autonomous Region lies on the northwestern border of China as one of the five ethnic minority autonomous regions of the country (Figure 1). It is a provincial administration with the largest land area in China, covering 1.66 million square kilometers and accounting for one-sixth of China's total land area. Xinjiang is located in the hinterland of the Eurasian continent and has a land border stretching over $5600 \mathrm{~km}^{2}$ with eight countries including Russia, Kazakhstan, Kyrgyzstan, Tajikistan, Pakistan, Mongolia, India, and Afghanistan. Xinjiang, a historically important trade route for the ancient Silk Road, now forms a crucial gateway in the second "Eurasian Land Bridge" with its strategic location.

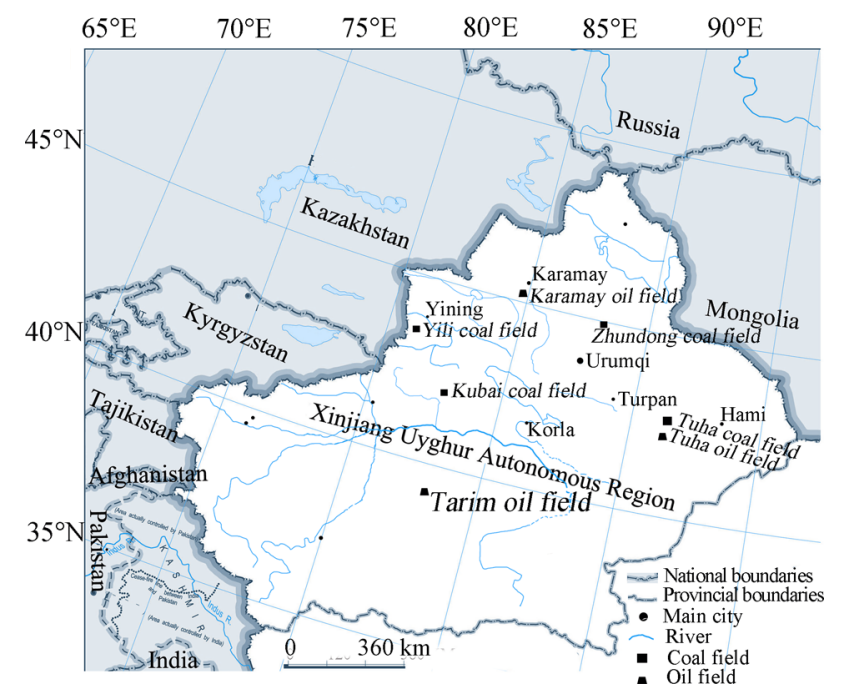

Figure 1 Location of Xinjiang Uygur Autonomous Region

Xinjiang has abundant reserves of energy resources. Based on the results of the Third National Coal Resources Forecast and Evaluation, the coal resources of Xinjiang amount to 2.19 trillion tons, accounting for $39 \%$ of the total national coal reserves, ranking first in China. According to the results of the Third National Oil and Gas Resources Evaluation, Xinjiang has 21.3 billion tons of crude oil prospective reserves and 10.8 trillion $\mathrm{m}^{3}$ of natural gas prospective reserves, accounting for $20 \%$ and $32 \%$ of total resource reserves for major petroliferous basins in China, respectively (Xiao, 2013). In the 12th Five-Year Plan, Xinjiang has aimed to build up the capacity to produce 50 million tons of crude oil, 100 billion $\mathrm{m}^{3}$ of natural gas and synthetic natural gas ( $\left.\mathrm{SNG}\right)$, and 30 million $\mathrm{kW}$ of power for external transfer. Moreover, large-scale oil and gas production and processing bases, coal-powered electricity and chemical plants, wind farms, and a major overland corridor for national energy resources will be established during this period. Xinjiang is rich in energy and mineral resources and also has abundant renewable energy resources, particularly wind and solar energy. According to the Xinjiang Uygur Autonomous Region Solar Photovoltaic Industry Development Plan (2011-2015), the theoretical potential reserve of solar energy (total solar radiation) in Xinjiang amounts to $5300-6700 \mathrm{MJ} \cdot \mathrm{m}^{-2} \cdot \mathrm{y}^{-1}$, the annual solar radiation of desert land area in Xinjiang can be equivalent to 4 thousand tons of standard coal. The avail- 
able exploitation area for wind power is approximately 0.156 million $\mathrm{km}^{2}$ (Ma et al., 2013), the exploitable installed capacity for wind resources in Xinjiang amounts to 93.4 million kW, accounting for $41 \%$ of the total domestic capacity (Zhang, 2008).

\section{Methodology}

\subsection{Structural Decomposition Analysis (SDA)}

The most commonly and extensively applied research methods for the scientific evaluation and quantitative analysis of the key factors of carbon emissions consist of index decomposition analysis (IDA) and structural decomposition analysis (SDA). The IDA model employs data aggregation to analyze the direct effects of changes in various factors including demographic, economic, and structural factors on carbon emissions (Ang, 1995; Ang and Zhang, 2000). The SDA model, based on the classical input-output theory (Casler and Rose, 1998; Dietzenbacher and Los, 1998; Rose and Casler, 1996), features greater data integrity and a more detailed analysis, which remedies the deficiency of the IDA model for its failure to analyze the indirect effects of the changes in final demand sectors on carbon emissions (Guan et al., 2009; Minx et al., 2011; Peters et al., 2007; Su and Ang, 2012). The SDA model has increasingly become the preferred research approach for domestic and international scholars to analyze the economics of energy-related carbon emissions. Peters et al. used the SDA model to analyze the factors of carbon emissions in China in 1992-2002 and found that the economic structure, technological level, and urban residential consumption have significant effects on carbon emissions (Peters et al., 2007). Minx et al. expanded the early work of Peters et al. (2007) to reveal that technological improvements in production sectors from 2002 to 2007 largely offset carbon emissions induced by final demand sectors (Minx et al., 2011). Guan et al., using the SDA model from a final demand perspective, found that urban residential consumption, investment in fixed assets, and export trading had significant impacts on the growth of carbon emissions in China from 2002 to 2007 (Guan et al., 2009).

Based on the input-output analysis, the SDA model is used to perform an in-depth analysis for the information of sectors contained in the input-output table and their interconnections. In this paper, an IO-SDA model was constructed to analyze the factors influencing energy-related carbon emissions in Xinjiang and the associated mechanisms. The analytical framework is presented as follows: The energy resource and environmental factors (carbon emissions) were included in an input-output table (Table 1). In addition, monetary input-output tables (MIOTs) were employed for the analysis of input and output, whereas physical input-output tables (PIOTs) were adopted for the analysis of energy resource and carbon emission factors, thereby establishing a hybrid input-output model for "energyeconomy-carbon emissions".

Based on the input-output theory, we constructed the SDA Model for the influencing factors of energy-related carbon emissions, as follows (Feng et al., 2015; Feng et al., 2012; Guan et al., 2008; Guan et al., 2009; Guan et al., 2014; Liang et al., 2014; Liang et al., 2013; Minx et al., 2011; Peters et al., 2007):

$$
C=E \times(I-A)^{-1} \times y
$$


Table 1 Energy-economy-carbon emission input-output model

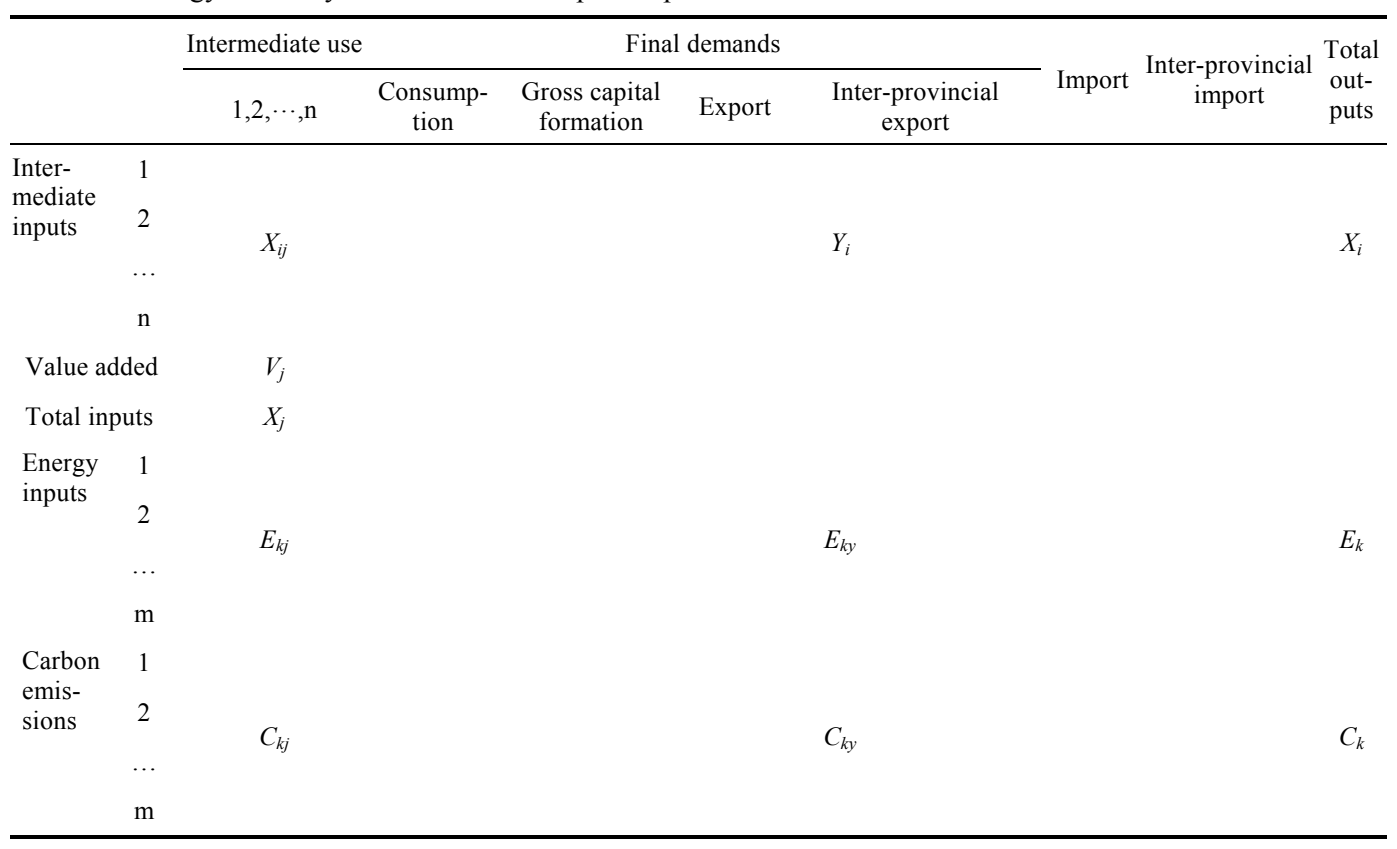

where $C$ represents total carbon emissions; $E$ represents carbon intensity vector on industrial scale; $A$ represents the $n \times n$ coefficient matrix of direct consumptions; $(I-A)^{-1}$ represents the $n \times n$ Leontief inverse matrix; and $y$ represents the final demand sectors in quadrant II of the input-output table, which comprised the final consumptions (i.e., government consumptions, urban household consumptions, and rural household consumptions), gross capital formation (i.e., fixed capital formation and inventory increase), and gross imports and exports (i.e., inter-provincial import, international import, inter-provincial export, and international export).

Among these, the $n \times 1$ column vector $y$ of the final demands can be further decomposed as the final demand structure $y_{s}$ and total final demand, whereby the latter can be further deposed as population size $P$ and per capita final demand $y_{v}$ (i.e. per capita GDP).

$$
\text { Therefore, } y=P \times y_{s} \times y_{v}
$$

Given the above, the SDA Model for energy-related carbon emissions can be derived as:

$$
C=E \times L \times y_{s} \times y_{v} \times P
$$

where $L=(I-A)^{-1}$ is the $n \times n$ Leontief inverse matrix.

Then,

$$
\begin{aligned}
\Delta C= & \Delta E \times L \times y_{s} \times y_{v} \times P+E \times \Delta L \times y_{s} \times y_{v} \times P+E \times L \times \Delta y_{s} \times y_{v} \times P+ \\
& E \times L \times y_{s} \times \Delta y_{v} \times P+E \times L \times y_{s} \times y_{v} \times \Delta P
\end{aligned}
$$

Subsequently,

$$
\Delta C=f(\Delta E)+f(\Delta L)+f\left(\Delta y_{s}\right)+f\left(\Delta y_{v}\right)+f(\Delta P)
$$

Based on the above, changes in carbon emissions $(\triangle C)$ were decomposed into five main influencing factors: population size $(P)$, carbon emission intensity $(E)$, production structure $(L)$, the final demand structure $\left(y_{s}\right)$, and per capita GDP $\left(y_{v}\right)$.

Advantages of the IO-SDA Model also include its ability to show the indirect effects of the final demand sectors on carbon emissions. Based on the categories of final demand sec- 
tors in the input-output table, the $n \times 1$ column vector $y$ of the final demand was diagonalized, and the following equation was derived:

$$
C_{k}=E \times(I-A)^{-1} \times y_{k}
$$

where $y_{k}$ represents the final demand of the $k$ type, $C_{k}$ represents the indirect carbon emission caused by changes in the final demand of the $k$ type.

\subsection{Data management}

The data in this study were mainly based on the input-output tables of Xinjiang in 1997, 2002, and 2007. Demographic, economic, and energy resource data were primarily sourced from the Xinjiang Uygur Autonomous Region Statistical Yearbook. To maintain consistency with sectoral energy consumption data from the statistical yearbook, the input-output tables of the 40 sectors in Xinjiang for 1997 and 42 sectors for 2002 and 2007 were consolidated based on certain industrial consolidation principles (Geng et al., 2013; Liang and Zhang, 2011 ) into a single input-output table with 28 sectors (Table 2). The double-deflation method (Guan et al., 2008; Liang et al., 2013; Minx et al., 2011; Peters et al., 2007) was further employed to convert input-output tables of Xinjiang for 2002 and 2007 to constant prices in 1997 to be able to compare the data between years.

Table 2 Input-output table of 28 industries in Xinjiang

\begin{tabular}{rl||rl}
\hline Code & \multicolumn{1}{c||}{ Industry } & Code & \multicolumn{1}{c}{ Industry } \\
\hline 1 & Agriculture & 15 & Metal products \\
2 & Coal mining and dressing & 16 & Common machines and special equipment manufacturing \\
3 & Oil and natural gas extraction & 17 & Traffic equipment manufacturing \\
4 & Metal ore mining & 18 & Electric equipment and parts manufacturing \\
5 & Non-metallic mineral mining & 19 & Computer, communications and other electronic \\
6 & Food processing and tobacco manufacturing & 20 & Instrument, meter and stationery manufacturing \\
7 & Textile & 21 & Other manufacturing \\
8 & $\begin{array}{l}\text { Manufacturing of clothes, leather, fur, feather } \\
\text { and other fiber products }\end{array}$ & 22 & Electric power and heat power production and supply \\
9 & Timber processing and furniture manufacturing & 23 & Gas production and supply \\
10 & $\begin{array}{l}\text { Paper making, printing, cultural and educa- } \\
\text { tional products manufacturing }\end{array}$ & 24 & Tap water production and supply \\
11 & Oil processing and refining & 25 & Construction \\
12 & Chemical materials and products manufacturing & 26 & Transportation, storage and telecommunications \\
13 & Non-metallic mineral processing & Metal smelting and rolling processing & Wholesale, retail and catering \\
14 & 28 & Other industries \\
\hline
\end{tabular}

\subsection{Calculation of energy-related based carbon emissions}

Based on the International Panel on Climate Change (IPCC) carbon emission calculation guide, with reference to the general default values and studies related to energy-related carbon emissions (Li and Chen, 2013; Zhang and Chen, 2014; Zhang et al., 2014), the main carbon emission coefficients were determined for use in the calculation of carbon emissions (Wang et al., 2014c; Wang et al., 2015), the equation is as follows: 


$$
C_{t}=\sum_{i} E_{t}^{i} \times L C V_{i} \times C F_{t}^{i} \times O_{i}
$$

where the superscript $t$ represents time, $i$ represents different types of energy, $C_{t}$ represents total carbon emissions (million tons) at time $t, E_{t}^{i}$ represents total consumption of the $i$ th type of energy at time $t$ (million tons), $L C V_{i}$ represents lower calorific value of the $i$ th type of energy, $C F_{t}^{i}$ represents carbon emission coefficient of the $i$ th type of energy, and $O_{i}$ represents combustion oxidation rate of the $i$ th type of energy (Table 3 ).

Table 3 Conversion factors, lower calorific value, and oxidation rate of energy sources

\begin{tabular}{lcccc}
\hline \multicolumn{1}{c}{ Energy sources } & $\begin{array}{c}\text { Conversion } \\
\text { factors }\end{array}$ & $\begin{array}{c}\mathrm{LCV} \\
\left.(\mathrm{MJ} / \mathrm{t} \text { or MJ/Mm})^{3}\right)\end{array}$ & Oxidation rate & $\begin{array}{c}\text { Carbon emission } \\
\text { factors (t C/TJ) }\end{array}$ \\
\hline Cleaned coal & $0.900 \mathrm{tce} / \mathrm{t}$ & 26.344 & 0.918 & 27.680 \\
Raw coal & $0.714 \mathrm{tce} / \mathrm{t}$ & 20.908 & 0.918 & 25.800 \\
Coke & $0.971 \mathrm{tce} / \mathrm{t}$ & 28.435 & 0.928 & 29.410 \\
Other washed coal & $0.286 \mathrm{tce} / \mathrm{t}$ & 8.363 & 0.918 & 25.800 \\
Crude oil & $1.429 \mathrm{tce} / \mathrm{t}$ & 41.816 & 0.979 & 20.080 \\
Fuel oil & $1.429 \mathrm{tce} / \mathrm{t}$ & 41.816 & 0.985 & 21.090 \\
Other petroleum products & $1.429 \mathrm{tce} / \mathrm{t}$ & 41.816 & 0.980 & 20.000 \\
Gasoline & $1.471 \mathrm{tce} / \mathrm{t}$ & 43.070 & 0.986 & 18.900 \\
Kerosene & $1.471 \mathrm{tce} / \mathrm{t}$ & 43.070 & 0.980 & 19.600 \\
Diesel oil & $1.457 \mathrm{tce} / \mathrm{t}$ & 42.652 & 0.982 & 20.170 \\
Nature gas & $1.330 \mathrm{tce} / 10^{3} \mathrm{~m}^{3}$ & 38.931 & 0.990 & 17.200 \\
Refinery gas & $1.571 \mathrm{tce} / \mathrm{t}$ & 46.055 & 0.989 & 18.200 \\
LPG & $1.714 \mathrm{tce} / \mathrm{t}$ & 50.179 & 0.989 & 17.200 \\
\hline
\end{tabular}

\section{Empirical analysis}

\subsection{Structural decomposition analysis of factors contributing to carbon emissions}

Based on the IPCC energy-related carbon emissions accounting system, the energy-related carbon emissions in Xinjiang increased from 20.70 million tons in 1997 to 24.08 million tons in 2002, and 40.34 million tons in 2007, showing an increase of $94.88 \%$ over 11 years. In particular, the increased amount of carbon emissions for the period 2002-2007 accounted for $82.79 \%$ of the total increase in carbon emissions over the period 1997-2007 (Figure 2). From 1997 to 2007, the growth in carbon emissions from the 28 industrial sectors of Xinjiang was mainly attributed to the energy production and processing industry, electric power and heat power production and supply, and mineral resources mining and processing industry. The growth of carbon emissions was mainly concentrated in the following industries:

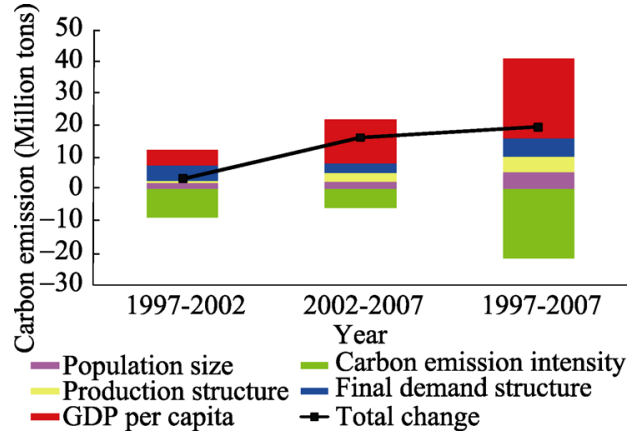

Figure 2 Structure decomposition analysis of various driving factors in Xinjiang from 1997 to 2007 
oil processing and refining (14.67 million tons), electric power and heat power production and supply (7.87 million tons), metal smelting and rolling processing (1.56 million tons), non-metallic mineral processing (1.01 million tons), and chemical materials and products manufacturing (0.66 million tons). These energy-intensive sectors and high-carbon industries should get the priority for energy savings and carbon emissions reduction efforts in the current, medium-term, and long-term industrial development of Xinjiang.

As shown in Figure 2, the results of the calculations by formulas (1), (2), (3), (4), and (5) are as follows: Changes in population size, per capita GDP, final demand structures, and production structures from 1997 to 2002 resulted in 2.28 million tons, 4.71 million tons, 4.72 million tons, and 0.64 million tons of increase in carbon emissions, respectively. Changes in carbon emission intensity led to a reduction of carbon emissions by 8.97 million tons. From 2002 to 2007, changes in population size, per capita GDP, final demand structures, and production structures caused 2.43 million tons, 13.63 million tons, 3.17 million tons, and 2.64 million tons of increase in carbon emissions, respectively. Changes in carbon emission intensity led to a reduction of carbon emissions by 5.62 million tons.

The rapid growth in per capita GDP had a significantly larger contribution to carbon emissions growth in the 2002-2007 period compared to the 1997-2002 period. The per capita GDP increased from 6052.39 yuan per person in 1997 to 8464.51 yuan per person in 2002 , and further increased to 16815.47 yuan per person in 2007 . This gives an annual per capita GDP growth of $6.87 \%$ in the $1997-2002$ period, and $12.35 \%$ in the $2002-2007$ period based on the calculations with comparable prices. Due to the scaling effects of rapid economic growth, the economic output was the most important factor contributing to the growth of carbon emissions in Xinjiang, during the 1997-2007 period. The reduction in carbon emissions contributed by the changes in carbon emission intensity had a significantly lower contribution in the 2002-2007 period compared with that in the 1997-2002 period. Carbon emission intensity in Xinjiang decreased from 199 tons of carbon/million yuan GDP in 1997 to 150 tons of carbon/million yuan GDP in 2002, and further decreased to 114 tons of carbon / million yuan GDP in 2007. The rate of decrease from 1997 to 2002 was 5.85\% annually, whereas the decrease from 2002 to 2007 was only $3.28 \%$ annually. The effects of population size on carbon emissions growth were not significantly different between the 1997-2002 and 2002-2007 periods, with this factor having a uniformly positive effect on carbon emissions growth in both periods. The effect of changes in the final demand structure on carbon emissions growth weakened in 2002-2007 compared with that in the 1997-2007 period. The effect of changes in the production structure became significantly stronger because the proportion of secondary industries in Xinjiang increased from $37.1 \%$ in 1997 to $46.8 \%$ in 2007 , whereas tertiary and primary industries decreased in proportion by varying degrees. Over the 1997-2007 period, the transformation strategy initialized in Xinjiang, i.e., the "advantageous resources transformation strategy" in the 9th Five-Year Plan, in which the development of new-type industries were underpinned and accelerated by the energy and mineral riches of Xinjiang. The full realization of the "Great Western Development Strategy" has brought about a significant increase in the level of investment in fixed assets, and further increases in the exploration and development of energy and mineral resources. The continuous expansion of energy and heavy chemical industries led to the current iteration of industrial structures in Xinjiang, which features rapid growth in secondary industries and a distinct inclination towards energy, mineral resources, and heavy chemical industries. Although the continued 
advancing of the new-type of industrialization has led to a decrease in energy consumption intensity in Xinjiang, from 301 tons of standard coal / million yuan GDP in 1997 to 224 tons of standard coal / million yuan GDP in 2002, and further to 186 tons of standard coal / million yuan GDP in 2007, the current energy consumption intensity is still over the national average, which further highlights the urgency of the transitioning to low-carbon production techniques.

From 1997 to 2007, the carbon emissions growth caused by changes in the per capita GDP, final demand structures, population size, and production structures contributed to $127.04 \%$, $28.78 \%, 27.63 \%$, and $25.48 \%$ of the total carbon emissions growth (Table 4 ). This implies that the continuous economic and population growth was not matched by effective optimizations and improvements in economic structure (final demand structures) and production techniques (production structure), thus leading to rapid growth in the energy-related carbon emissions of Xinjiang. Over the same period (1997-2007), the absolute value of carbon emission reductions contributed by the reductions in carbon emission intensity was $108.92 \%$; carbon intensity is the only factor that had a suppressive effect on the growth of carbon emissions within this time period.

Table 4 Structure decomposition analysis of contributions of various driving factors in Xinjiang

\begin{tabular}{lccc}
\hline \multicolumn{1}{c}{ Influencing factors } & Stage: $1997-2002$ & Stage: $2002-2007$ & Stage: 1997-2007 \\
\hline Population size & 67.49 & 14.96 & 27.63 \\
GDP per capita & 139.24 & 83.82 & 127.04 \\
Final demand structure & 139.57 & 19.50 & 28.78 \\
Production structure & 19.02 & 16.25 & 25.48 \\
Carbon emission intensity & -265.33 & -34.54 & -108.92 \\
Total change & 100.00 & 100.00 & 100.00 \\
\hline
\end{tabular}

\subsection{Structural decomposition analysis of the influences of various categories of final demands on carbon emissions growth}

Based on the calculation results using formula (6), the indirect effects due to changes in various final demands on overall energy-related carbon emissions and on carbon emissions of the individual industrial sectors were analyzed (Figure 3, Tables 5 and 6).

From a final demands perspective, interprovincial trade outflow and inflow and gross fixed capital formation have significant impacts on energy-related carbon emissions. The effect that household consumption has on energy-related carbon emissions growth has also become more evident over time, especially the effect of the consumption of urban households.

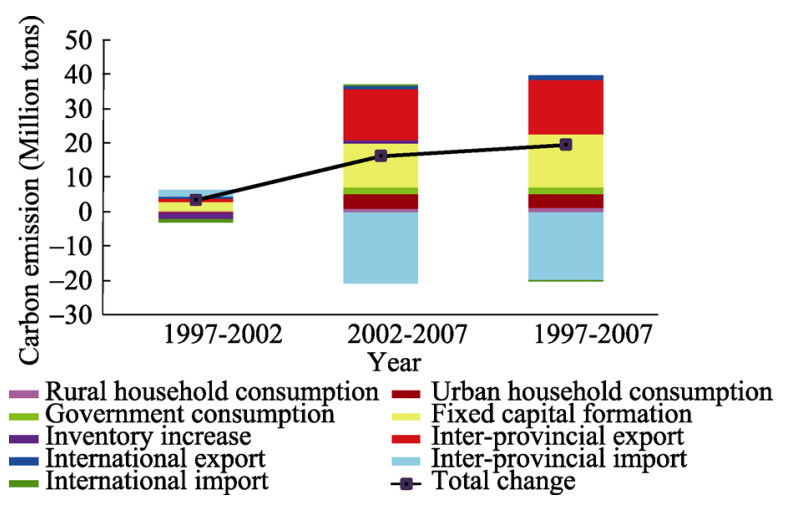

Figure 3 Increment of carbon emissions from different final demands in Xinjiang 
Table 5 Contribution to carbon emissions of different final demands in Xinjiang

\begin{tabular}{lccc}
\hline \multicolumn{1}{c}{ Final demands } & Stage: $1997-2002$ & Stage: $2002-2007$ & Stage: $1997-2007$ \\
\hline Rural household consumption & 9.31 & 6.72 & 7.10 \\
Urban household consumption & -10.90 & 24.59 & 19.32 \\
Government consumption & -1.36 & 12.51 & 10.45 \\
Fixed capital formation & 76.41 & 78.45 & 78.15 \\
Inventory increase & -47.64 & 7.67 & -0.54 \\
Inter-provincial export & 28.20 & 90.52 & 81.27 \\
International export & 16.55 & 5.22 & 6.90 \\
Inter-provincial import & 63.09 & -128.10 & -99.72 \\
International import & -33.65 & 2.42 & -2.93 \\
Total change & 100 & 100 & 100 \\
\hline
\end{tabular}

Table 6 Carbon emission changes caused by different final demands from different sectors in Xinjiang (Million tons)

\begin{tabular}{|c|c|c|c|c|c|c|c|c|c|}
\hline Code & $\begin{array}{c}\text { Rural } \\
\text { household } \\
\text { consumption }\end{array}$ & $\begin{array}{c}\text { Urban } \\
\text { household } \\
\text { consumption }\end{array}$ & $\begin{array}{l}\text { Government } \\
\text { consump- } \\
\text { tion }\end{array}$ & $\begin{array}{c}\text { Fixed } \\
\text { capital } \\
\text { formation }\end{array}$ & $\begin{array}{c}\text { Inven- } \\
\text { tory } \\
\text { increase }\end{array}$ & $\begin{array}{l}\text { Inter- } \\
\text { provincial } \\
\text { export }\end{array}$ & $\begin{array}{l}\text { Inter- } \\
\text { national } \\
\text { export }\end{array}$ & $\begin{array}{l}\text { Inter- } \\
\text { provincial } \\
\text { import }\end{array}$ & $\begin{array}{c}\text { Interna- } \\
\text { tional } \\
\text { import }\end{array}$ \\
\hline 1 & 0.1873 & -0.0669 & 0.0313 & -0.0868 & -0.81 & 1.6655 & 0.882 & 0.1552 & 0.0321 \\
\hline 2 & 0.0537 & -0.0201 & 0 & 0 & -0.0318 & 0.0038 & -0.0002 & 0.2869 & -0.0008 \\
\hline 3 & -0.0019 & 0.0117 & 0 & 0 & -0.2239 & -0.1839 & 0.0292 & 0.0623 & -0.1864 \\
\hline 4 & 0 & 0 & 0 & 0 & 0.0213 & 0.241 & -0.0007 & -0.0005 & -0.0969 \\
\hline 5 & 0 & 0 & 0 & 0 & -0.0013 & -0.0375 & 0.0052 & 0.1472 & 0.0003 \\
\hline 6 & -0.0058 & 0.3353 & 0 & 0 & -0.0855 & -0.165 & 0.1344 & 0.1263 & -0.001 \\
\hline 7 & 0.0269 & 0.0097 & 0 & 0 & 0.068 & -0.4603 & -0.1237 & -0.0093 & 0.0022 \\
\hline 8 & 0.0386 & 0.1053 & 0 & 0 & 0.0038 & -0.1112 & -0.0301 & -0.0449 & -0.0379 \\
\hline 9 & 0.0162 & 0.0125 & 0 & 0.097 & 0.0266 & -0.0049 & 0.0925 & -0.2857 & -0.0261 \\
\hline 10 & 0.0014 & -0.0493 & 0 & 0 & 0.005 & -0.0275 & -0.0101 & -0.3415 & 0.0299 \\
\hline 11 & 0.1111 & -0.0118 & 0 & 0 & 0.1641 & 10.2867 & -0.068 & 0.249 & -0.0058 \\
\hline 12 & 0.0626 & 0.2982 & 0 & 0 & 0.1675 & 1.7326 & -0.0134 & -1.697 & -0.0559 \\
\hline 13 & 0.196 & 0.1256 & 0 & 0 & 0.0477 & -0.0265 & 0.0385 & -0.846 & -0.0038 \\
\hline 14 & 0 & -0.0864 & 0 & 0 & 0.0245 & 1.8133 & 0.1983 & -3.136 & 0.3263 \\
\hline 15 & 0.0015 & 0.0133 & 0 & 1.3395 & 0.2181 & 0.0153 & -0.0183 & -1.9461 & -0.1637 \\
\hline 16 & -0.0002 & 0.0545 & 0 & 1.9104 & 0.2553 & -0.1399 & -0.0097 & -3.1638 & -0.1218 \\
\hline 17 & 0.059 & 0.0614 & 0 & -0.1649 & -0.0067 & -0.283 & 0.0506 & 0.9186 & 0.0095 \\
\hline 18 & 0.006 & 0.0176 & 0 & 0.4871 & 0.0625 & 0.4347 & 0.0078 & -0.4661 & -0.0428 \\
\hline 19 & 0.1216 & 0.6217 & 0 & 2.068 & 0.0599 & 0.3134 & 0.041 & -3.9085 & -0.1327 \\
\hline 20 & 0.0028 & -0.0142 & 0 & -0.0112 & 0.0466 & -0.0008 & -0.0013 & -0.0819 & -0.0496 \\
\hline 21 & 0.0024 & 0.0564 & 0 & 0 & -0.0115 & -0.0874 & 0.0034 & -0.1143 & 0.0323 \\
\hline 22 & 0.1893 & 1.0403 & 0 & 0 & -0.0022 & -0.0823 & 0 & 0.1589 & 0 \\
\hline 23 & 0.0015 & 0.0255 & 0 & 0 & -0.0052 & -0.0596 & 0 & 0.0031 & 0 \\
\hline 24 & 0.012 & 0.0212 & 0 & 0 & 0 & 0 & 0 & 0.0037 & 0 \\
\hline 25 & 0.07 & 0 & 0 & 9.4413 & 0 & 0.0013 & 0 & -2.3583 & 0 \\
\hline 26 & 0.1719 & 0.6526 & 0.2587 & -0.2954 & -0.0605 & 1.6285 & 0.0197 & -0.8819 & -0.0428 \\
\hline 27 & -0.1495 & -0.2458 & 0.0004 & 0.006 & -0.0392 & -0.5082 & 0.1278 & -0.8033 & -0.0408 \\
\hline 28 & 0.2213 & 0.8268 & 1.7628 & 0.5593 & 0.0006 & 0.0055 & 0 & -1.6142 & 0 \\
\hline Total change & 1.3955 & 3.7952 & 2.0532 & 15.3504 & -0.1063 & 15.9637 & 1.355 & -19.5881 & -0.5761 \\
\hline
\end{tabular}


From 1997 to 2007, interprovincial trade outflow and inflow had far greater influence on carbon emissions as compared to international exports and imports in Xinjiang. International exports caused larger increases of carbon emissions than the reductions in carbon emissions caused by international imports, whereas domestic exports led to lower carbon emissions growth than the carbon emissions reductions induced by domestic imports. Interprovincial trade outflow (i.e. interprovincial exports) from 1997 to 2007 in Xinjiang has caused a carbon emissions growth of 15.96 million tons, which is $81.27 \%$ of the total carbon emissions growth within that period. Therefore, interprovincial trade outflow is the single most important factor that contributes to carbon emissions growth. Conversely, interprovincial trade inflow (i.e. interprovincial imports) reduced carbon emissions by 19.59 million tons, which is $99.72 \%$ (in terms of absolute value) of the change in carbon emissions from 1997 to 2007 , and is therefore the largest contributor to carbon emissions reduction within this period. From 1997 to 2007, the sectors that made up the bulk of the 15.96 million tons of carbon emissions growth caused by interprovincial trade outflow are: the oil processing and refining industry (10.29 million tons), the metal smelting and rolling processing (1.81 million tons), chemical materials and chemical products manufacturing (1.73 million tons), and agriculture (1.67 million tons). The main sectors that contributed to the 19.59 million tons of carbon emissions reduction in this period are: the manufacturing of communications equipment, computers, and other electronic equipment (3.91 million tons), the common machines and special equipment manufacturing (3.16 million tons), and the metal foundries and presses industry (3.14 million tons). The net carbon emissions growth due to interprovincial trade outflow and inflow was -3.62 million tons.

The international exports led to 1.36 million tons of carbon emissions growth in the 1997-2007 period, with the main contributors being agriculture ( 0.88 million tons), the metal smelting and rolling processing (0.20 million tons), and the food manufacturing and tobacco processing industry ( 0.13 million tons). The international imports reduced carbon emissions by 0.58 million tons, with the main source of these reductions coming from the oil and gas exploration industry (0.19 million tons) and the metal products industry (0.16 million tons). The net balance of international trade was 0.78 million tons, which accounted for $3.97 \%$ of the growth of carbon emissions from 1997 to 2007 . The main mode of the international trade in Xinjiang from 1997 to 2007 was the small-scale cross border trade, with 9.42 billion U.S. dollars in 2007, which accounts for $68.65 \%$ of all trade passing through Xinjiang customs. The main trade partners were Central Asian countries, Kazakhstan and Kyrgyzstan being the major ones. The exported goods were mainly electronics, shoes, textiles and apparel, and steel and agricultural products, while the imported goods were mainly petroleum, natural gas, and mineral resources.

The growth in carbon emissions caused by the gross fixed-capital formation from 1997 to 2007 in Xinjiang was 15.35 million tons, accounting for $78.15 \%$ of the total carbon emissions growth during that period. The carbon emissions growth arising from the gross fixed-capital formation was mainly concentrated in the construction industry (9.44 million tons), communications equipment manufacturing (2.07 million tons), the common machines and special equipment manufacturing (1.91 million tons), and the metal products industry (1.34 million tons). The gross fixed-capital formation in Xinjiang increased from 46.14 billion yuan to 85.67 billion yuan in 2002, and rapidly increased further to 200.50 billion yuan 
in 2007, mainly in industries that consume large amounts of energy, such as the construction industry, equipment manufacturing industry, and metal products industry. It is therefore important to prioritize carbon emissions reduction and energy conservation in the construction industry, and to improve the production technology in the equipment manufacturing and metal fabricating industries, for the implementation of low-carbon development in Xinjiang.

The carbon emissions growth induced by the household consumption from 1997 to 2007 was 5.19 million tons, with the consumption of urban and rural households accounting for 3.80 million tons and 1.40 million tons of that growth, respectively. The growth in urban household carbon emissions was mainly from the production and supply of electricity and heating (1.04 million tons), other tertiary industries (0.83 million tons), and the transportation, storage, and telecommunications sectors ( 0.65 million tons). The growth in rural household carbon emissions was mainly due to other tertiary industries (0.22 million tons), the non-metallic mineral products industry ( 0.20 million tons), and the production and supply of electricity and heating ( 0.19 million tons). With rapid urbanization, a large portion of the rural population has migrated into urban areas and the urbanization level of Xinjiang has increased from $35.20 \%$ in 1997 to $35.91 \%$ in 2002 , and further to $39.15 \%$ in 2007 . The average consumption level of urban residents increased from 3328 yuan per person in 1997 to 8986 yuan per person in 2007. At the same time, the consumption level of rural residents also increased from 1891 yuan per person in 1997 to 2320 yuan per person in 2007. The consumption gap between rural and urban residents has continued to increase over time, which explains why the consumption of urban households accounts for a much larger portion of carbon emissions growth than that of rural households. With the continued progression of the "new-type urbanization", the consumption level of urban residents and their demands on the production and supply of electricity and heating, transportation, storage, and telecommunication industries will continue to increase. It is therefore of utmost importance to make improvements to the thermal power plants and coal-fired heating systems and to reduce carbon emissions and energy consumption in the transportation industry.

Interprovincial trade outflow has had a significant indirect effect upon the carbon emissions of Xinjiang far exceeding the emissions associated with international exports. The main contributors to these indirect effects are energy-intensive industries, such as the oil processing and refining industry, the metal smelting and rolling processing industry, and the chemical products industry, as well as the interprovincial trade outflow of agricultural products. The rapid development of energy-intensive industries and investments within this sector in Xinjiang is a consequence of its abundance in resources, cost advantages, and market demands. Xinjiang is very rich in coal, oil, and mineral deposits and have relatively low labor and land costs. The total social investment in fixed assets in Xinjiang increased from 44.68 billion yuan to 81.30 billion yuan in 2002, and rapidly increased to 185.08 billion yuan in 2007. The investment was primarily focused on energy-intensive industries, such as mining, manufacturing, and the production and supply of heat and electricity. In 2007, the fixed asset investments in the oil and gas exploration industry, the petroleum processing and coking industry, and the production and supply of electricity and heating accounted for $19.49 \%, 7.63 \%$, and $5.69 \%$ of the total social investment in fixed assets, respectively. From 1997 to 2007, crude oil processing capacities increased from 8.51 million tons to 17.05 million tons, gasoline production increased from 2.08 million tons to 2.77 million 
tons, diesel production increased from 3.04 million tons to 8.20 million tons, cement production increased from 6.28 million tons to 15.37 million tons, and steel production increased from 1.00 million tons to 4.71 million tons. The domestic export of energy resource-based products from Xinjiang caused a noticeable shift in regional "embodied carbon emissions". As the various regions of China are dependent on each other (Feng et al., 2013; Liu et al., 2015a; Liu et al., 2015b), the supply of energy resource-based products from Xinjiang to other provinces has increased the reliance of Xinjiang on the domestic market up to a certain degree. This has resulted in the interprovincial trade outflow having a significant effect on the carbon emissions growth of Xinjiang.

The regional shift of "embodied carbon emissions" (Li et al., 2013; Liu Weidong et al., 2012; Liu et al., 2010; Tang et al., 2014) due to domestic export of energy resource-based products, and the direct domestic export of energy resources are both detrimental to low-carbon development projects in the Xinjiang region. Since 2007, the energy consumption of Xinjiang has rapidly grown, especially the energy obtained from high-carbon resources such as coal. On the other hand, the growth in the consumption of energy from lower-carbon emission resources such as petroleum has been relatively slow (Figure 4, Top). Overall domestic energy exports from Xinjiang have rapidly increased since 2007 (Figure 4, Down). The domestic export of oil has maintained a state of continuous growth, with almost all of the oil produced in this region being exported. The volume of coal outflow has also exhibited a rapid growth since 2007. In the 12th Five-Year Plan, Shanxi, the Ordos Basin,

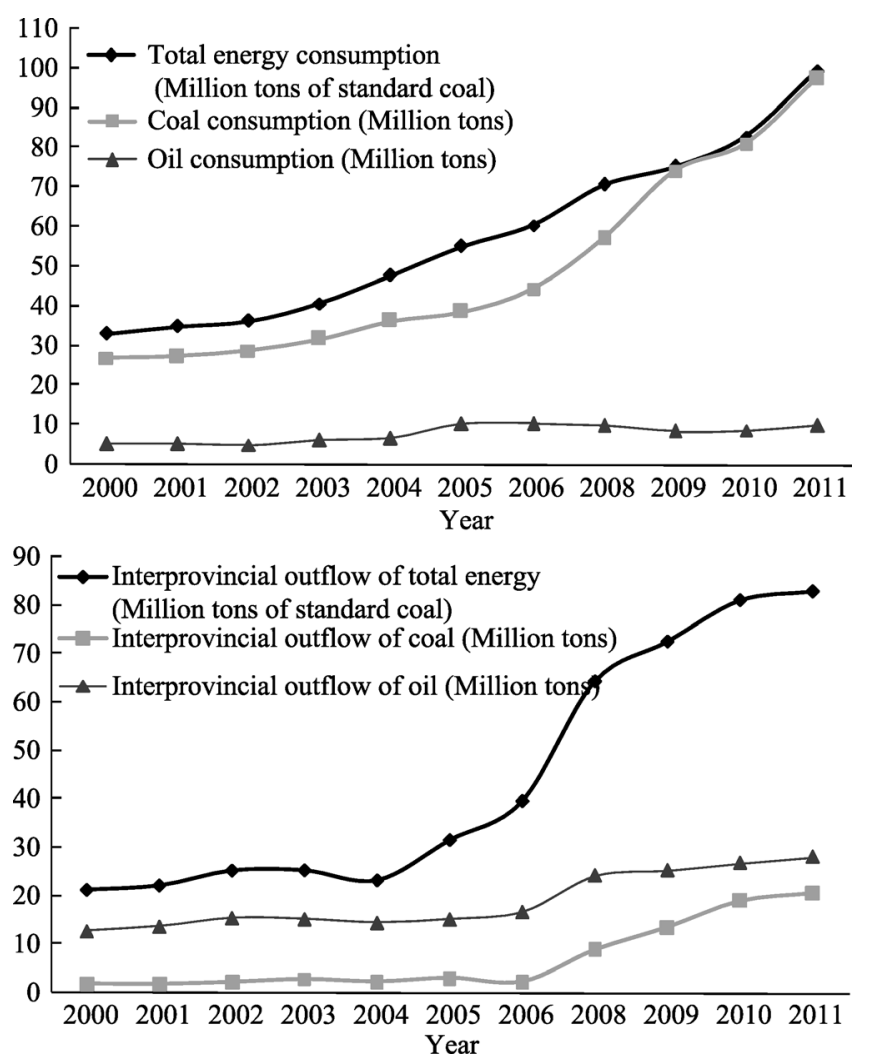

Figure 4 Energy consumption (Top) and energy outflow (Down) in Xinjiang from 2000 to 2011 
Eastern Inner Mongolia, Southwest China, and Xinjiang were designated as the five national integrated energy bases of China. The Xinjiang base is the farthest of these bases from the primary consumption regions in China, and thus has the longest transportation distances that will result in enormous transportation costs. Therefore, Xinjiang should implement the appropriate differentiated energy-savings and carbon emissions reduction targets in the current and future growth periods.

\section{Conclusions}

An analytical framework based on the "energy-economy-carbon emissions" hybrid model was constructed using the classical input-output theory. An input output-structural decomposition analysis model was used to perform a decomposition analysis of the factors that impact energy-related carbon emissions in Xinjiang from 1997 to 2007.

From 1997 to 2007, energy-related carbon emissions of Xinjiang increased from 20.70 million tons in 1997 to 24.08 million tons in 2002, and further increased to 40.34 million tons in 2007 , showing an overall increase of $94.88 \%$ over 11 years. The main sources were the production and processing of energy resources as well as the mining and processing of mineral resources.

The results on the direct effects of factors impacting carbon emissions showed that changes in per capita GDP, final demand structures, production structures, and population size were the main factors that contributed to carbon emissions growth, whereas the decrease in carbon emission intensity was an important factor in suppressing the growth of emissions during this period. This implies that the continuous economic and population growth was not matched by optimizations in economic structure (final demand structure) and improvements in production techniques (production structure), which led to the rapid growth of carbon emissions in Xinjiang.

The analyses of the indirect effects of factors on carbon emissions from the final demand perspective revealed that domestic interprovincial trade outflow and inflow as well as gross fixed-capital formation have a significant impact on changes in the energy-related carbon emissions of Xinjiang. At the same time, the contribution of household consumption, especially the urban household consumption, to the growth of energy-related carbon emissions in Xinjiang is increasing. The increase in fixed capital investment in high-carbon industry sectors, and the growth in interprovincial trade outflow of energy resource-based products had a significant impact on the shifting of regional "embodied carbon emissions".

With the new-type urbanization of Xinjiang and the promotion of new industrialization processes, as well as the implementation of the "Xinjiang Aid Policy" and the complete rebuilding of the "Silk Road Economic Belt", the urbanization and industrialization levels and the total investment in fixed assets are expected to continue to increase. In the context of China's western development and Xinjiang's leapfrog development, a comprehensive analysis of the leading industries in the various prefectures of Xinjiang was performed. The results showed that most of these industries including coal production, coal-to-chemical production, petroleum processing, equipment manufacturing, the steel industry, cement manufacturing, electrolytic aluminum production, the polysilicon industry, light industry, and textiles manufacturing were reliant on resource and cost advantages. It remains to be seen 
whether it is possible to convert these energy and mineral resource advantages into economic advantages and whether the knowledge from developed regions such as eastern and central China will lead to technological improvements in the energy- and resource-intensive industries of Xinjiang for the implementation of sustainable and low-carbon development.

The effective utilization of industry correlation effects, such as driving the development of regional competitive processing industries that are currently reliant on local markets by prompting the development of energy and raw material industries, will have a profound impact on the transformation of economic structures in Xinjiang to a low-carbon economy. With the large influx of investment in Xinjiang, more work should be performed to upgrade the production processes and to eliminate the outdated production infrastructure. To enable the adoption of low-carbon techniques and energy saving measures in national industrial parks and new industrial districts, the government of the autonomous region and the energy resource sector should prioritize the hiring of top-tier talent for research and development work, especially in industries involved in electricity generation, new energy resources, modern chemical manufacturing, new materials, and high-end equipment manufacturing. While fossil fuels are currently being used intensively, the usage of renewable energy resources should be simultaneously expanded, through comprehensive plans for the development and distribution of solar and wind energy. Renewable energy systems should be planned and established for industrial parks of a larger scale, as well as for densely-populated residential areas.

The domestic export of energy resource-based products, which causes a regional shift in "embodied carbon emissions", and the direct (domestic) export of energy resources are detrimental to the low-carbon development in the Xinjiang region. The progress in technological improvements, in the replacement of high-carbon energy sources with renewable, low-carbon energy sources, and in the reduction of carbon emissions and energy consumption in key industries is slow. Therefore, the following key questions should be answered before deciding on the main focus of the energy and carbon emissions reduction: How should an integrated energy base be built? How can the needs of local consumption and the energy export be reconciled? How can low-carbon energy sources (oil and natural gas) be obtained in larger quantities? Xinjiang should implement differentiated energy-savings and emission reduction goals, while taking into consideration the interdependence of the various regions, the continuous increase in domestic energy exports, and high costs of energy transport over long distances.

In the arid northwestern region, water is a key factor that restricts socio-economic development. The high-carbon industries of Xinjiang, such as coal production, coal chemical production, oil processing and refining, and metal foundries and presses are also highly water-intensive. It is thus necessary to pay close attention to the preservation of water resources, thereby restricting water usage in the development of energy-intensive industries in arid regions.

\section{References}

Akimoto Hajime, Ohara Toshimasa, Kurokawa Jun-ichi et al., 2006. Verification of energy consumption in China during 1996-2003 by using satellite observational data. Atmospheric Environment, 40(40): 7663-7667.

Al-mulali Usama, 2012. Factors affecting $\mathrm{CO}_{2}$ emission in the Middle East: A panel data analysis. Energy, 44(1): $564-569$.

Al-mulali Usama, Sab Che Normee Binti Che, 2012. The impact of energy consumption and $\mathrm{CO}_{2}$ emission on the economic growth and financial development in the Sub Saharan African countries. Energy, 39(1): 180-186. 
Aldy Joseph E, Stavins Robert N, 2012. Climate negotiators create an opportunity for scholars. Science, 337(6098): 1043-1044.

Ang B W, 1995. Decomposition methodology in industrial energy demand analysis. Energy, 20(11): 1081-1095.

Ang B W, Zhang F Q, 2000. A survey of index decomposition analysis in energy and environmental studies. Energy, 25(12): 1149-1176.

Casler Stephen D, Rose Adam, 1998. Carbon dioxide emissions in the U.S. economy: A structural decomposition analysis. Environmental and Resource Economics, 11(3/4): 349-363.

Cheng Yeqing, Wang Zheye, Ye Xinyue et al., 2014. Spatiotemporal dynamics of carbon intensity from energy consumption in China. Journal of Geographical Sciences, 24(4): 631-650.

Chu Steven, Majumdar Arun, 2012. Opportunities and challenges for a sustainable energy future. Nature, 488(7411): 294-303.

Chuai Xiaowei, Huang Xianjin, Wang Wanjing et al., 2012. Spatial econometric analysis of carbon emissions from energy consumption in China. Journal of Geographical Sciences, 22(4): 630-642.

Cyranoski David, 2007. China struggles to square growth and emissions. Nature, 446(7139): 954-955.

Dietzenbacher Erik, Los Bart, 1998. Structural decomposition techniques: Sense and sensitivity. Economic Systems Research, 10(4): 307-324.

Du Huibin, Guo Jianghong, Mao Guozhu et al., 2011. $\mathrm{CO}_{2}$ emissions embodied in China-US trade: Input-output analysis based on the emergy/dollar ratio. Energy Policy, 39(10): 5980-5987.

Feng Kuishuang, Davis Steven J, Sun Laixiang et al., 2013. Outsourcing $\mathrm{CO}_{2}$ within China. Proceedings of the National Academy of Sciences, 110(28): 11654-11659.

Feng Kuishuang, Davis Steven J, Sun Laixiang et al., 2015. Drivers of the US $\mathrm{CO}_{2}$ emissions 1997-2013. Nature Communications, (6): 7714.

Feng Kuishuang, Siu Yim Ling, Guan Dabo et al., 2012. Analyzing drivers of regional carbon dioxide emissions for China. Journal of Industrial Ecology, 16(4): 600-611.

Geng Yong, Zhao Hongyan, Liu Zhu et al., 2013. Exploring driving factors of energy-related $\mathrm{CO}_{2}$ emissions in Chinese provinces: A case of Liaoning. Energy Policy, 60: 820-826.

Gregg Jay S, Andres Robert J, Marland Gregg, 2008. China: Emissions pattern of the world leader in $\mathrm{CO}_{2}$ emissions from fossil fuel consumption and cement production. Geophysical Research Letters, 35(8): L08806.

Guan Dabo, Hubacek Klaus, Weber Christopher L et al., 2008. The drivers of Chinese $\mathrm{CO}_{2}$ emissions from 1980 to 2030. Global Environmental Change, 18(4): 626-634.

Guan Dabo, Peters Glen P, Weber Christopher L et al., 2009. Journey to world top emitter: An analysis of the driving forces of China's recent $\mathrm{CO}_{2}$ emissions surge. Geophysical Research Letters, 36(4): L04709.

Guan Dabo, Su Xin, Zhang Qiang et al., 2014. The socioeconomic drivers of China's primary $\mathrm{PM}_{2.5}$ emissions. Environmental Research Letters, 9(2): 024010.

He Gang, Avrin Anne-Perrine, Nelson James H et al., 2016. SWITCH-China: A systems approach to decarbonizing China's power system. Environmental Science \& Technology, 50(11): 5467-5473.

Jiang Bing, Sun Zhenqing, Liu Meiqin, 2010. China's energy development strategy under the low-carbon economy. Energy, 35(11): 4257-4264.

Le Quéré Corinne, Raupach Michael R, Canadell Josep G et al., 2009. Trends in the sources and sinks of carbon dioxide. Nature Geoscience, 2(12): 831-836.

Li Fangyi, Liu Weidong, Tang Zhipeng, 2013. Study on inter-regional transfer of embodied pollution in China. Acta Geographica Sinica, 68(6): 791-801. (in Chinese)

Li Huanan, Mu Hailin, Zhang Ming et al., 2011. Analysis on influence factors of China's $\mathrm{CO}_{2}$ emissions based on Path-STIRPAT model. Energy Policy, 39(11): 6906-6911.

Li Huanan, Mu Hailin, Zhang Ming et al., 2012. Analysis of regional difference on impact factors of China's energy-related $\mathrm{CO}_{2}$ emissions. Energy, 39(1): 319-326.

Li J S, Chen G Q, 2013. Energy and greenhouse gas emissions review for Macao. Renewable and Sustainable Energy Reviews, 22: 23-32.

Liang Sai, Liu Zhu, Crawford-Brown Douglas et al., 2014. Decoupling analysis and socioeconomic drivers of environmental pressure in China. Environmental Science \& Technology, 48(2): 1103-1113.

Liang Sai, Xu Ming, Liu Zhu et al., 2013. Socioeconomic drivers of mercury emissions in China from 1992 to 
2007. Environmental Science \& Technology, 47(7): 3234-3240.

Liang Sai, Zhang Tianzhu, 2011. What is driving $\mathrm{CO}_{2}$ emissions in a typical manufacturing center of South China? The case of Jiangsu Province. Energy Policy, 39(11): 7078-7083.

Liu Hongguang, Liu Weidong, Fan Xiaomei et al., 2015a. Carbon emissions embodied in value added chains in China. Journal of Cleaner Production, 103: 362-370.

Liu Hongguang, Liu Weidong, Fan Xiaomei et al., 2015b. Carbon emissions embodied in demand-supply chains in China. Energy Economics, 50: 294-305.

Liu Weidong, Song Zhouying, Liu Zhigao, 2016. Progress of economic geography in China's mainland since 2000. Journal of Geographical Sciences, 26(8): 1019-1040.

Liu Weidong, Liu Hongguang, Fan Xiaomei et al., 2012. Sector-specific spatial statistic model for estimating inter-regional trade Flows: A case study of agricultural, chemical and electronic sectors in China. Acta Geographica Sinica, 67(2): 147-156. (in Chinese)

Liu Weidong, Liu Hongguang, Tang Zhipeng et al., 2010. The impacts of exports on regional economic development and industrial restructuring in China. Acta Geographica Sinica, 65(4): 407-415. (in Chinese)

Liu Yansui, Yan Bin, Zhou Yang, 2016. Urbanization, economic growth, and carbon dioxide emissions in China: A panel cointegration and causality analysis. Journal of Geographical Sciences, 26(2): 131-152.

Liu Zhu, Liang Sai, Geng Yong et al., 2012. Features, trajectories and driving forces for energy-related GHG emissions from Chinese mega cites: The case of Beijing, Tianjin, Shanghai and Chongqing. Energy, 37(1): 245-254.

Ma Zhixiao, Xue Bing, Geng Yong et al., 2013. Co-benefits analysis on climate change and environmental effects of wind-power: A case study from Xinjiang, China. Renewable Energy, 57: 35-42.

Malakoff David, 2014. China's peak carbon pledge raises pointed questions. Science, 346(6212): 903.

Minx Jan C, Baiocchi Giovanni, Peters Glen P et al., 2011. A “Carbonizing Dragon”: China's fast growing $\mathrm{CO}_{2}$ emissions revisited. Environmental Science \& Technology, 45(21): 9144-9153.

O'Neill Brian C, Dalton Michael Fuchs Regina et al., 2010. Global demographic trends and future carbon emissions. Proceedings of the National Academy of Sciences, 107(41): 17521-17526.

Peters Glen P, Andrew Robbie M, Boden Tom et al., 2013. The challenge to keep global warming below 2 [deg]C. Nature Clim. Change, 3(1): 4-6.

Peters Glen P, Weber Christopher L, Guan Dabo et al., 2007. China's growing $\mathrm{CO}_{2}$ emissions A race between increasing consumption and efficiency gains. Environmental Science \& Technology, 41(17): 5939-5944.

Piao Shilong, Ciais Philippe, Huang Yao et al., 2010. The impacts of climate change on water resources and agriculture in China. Nature, 467(7311): 43-51.

Qiu Jane, 2008. China asks world to step up on climate. Nature, 456(7219): 151.

Qiu Jane, 2009. China's climate target: Is it achievable? Nature, 462(7273): 550-551.

Qiu Jane, 2011. China unveils green targets. Nature, 471(7337): 149.

Rose Adam, Casler Stephen, 1996. Input-output structural decomposition analysis: A critical appraisal. Economic Systems Research, 8(1): 33-62.

Shen Lei, Sun Yanzhi, 2016. Review on carbon emissions, energy consumption and low-carbon economy in China from a perspective of global climate change. Journal of Geographical Sciences, 26(7): 855-870.

Streets David G, Jiang Kejun, Hu Xiulian et al., 2001. Recent reductions in China's greenhouse gas emissions. Science, 294(5548): 1835-1837.

Su Bin, Ang B W, 2012. Structural decomposition analysis applied to energy and emissions: Some methodological developments. Energy Economics, 34(1): 177-188.

Su Bin, Ang B W, Low M, 2013. Input-output analysis of $\mathrm{CO}_{2}$ emissions embodied in trade and the driving forces: Processing and normal exports. Ecological Economics, 88: 119-125.

Tang Zhipeng, Liu Weidong, Gong Peiping, 2014. Measuring of Chinese regional carbon emission spatial effects induced by exports based on Chinese multi-regional input-output table during 1997-2007. Acta Geographica Sinica, 69(10): 1403-1413.

Tollefson Jeff, 2015. The 2 degrees C dream. Nature, 527(7579): 436-438.

Wang Changjian, Wang Fei, Li Lianrong et al., 2013. Wake-up call for China to re-evaluate its shale-gas ambition. Environmental Science \& Technology, 47(21): 11920-11921. 
Wang Changjian, Wang Fei, Du Hongru et al., 2014a. Is China really ready for shale gas revolution: Re-evaluating shale gas challenges. Environmental Science \& Policy, 39: 49-55.

Wang Changjian, Wang Fei, Zhang Hongou et al., 2014b. China's carbon trading scheme is a priority. Environmental Science \& Technology, 48(23): 13559.

Wang Changjian, Wang Fei, Zhang Hongou et al., 2014c. Carbon emissions decomposition and environmental mitigation policy recommendations for sustainable development in Shandong Province. Sustainability, 6(11): 8164-8179.

Wang Changjian, Wang Fei, Zhang Hongou, 2016. The process of energy-related carbon emissions and influencing mechanism research in Xinjiang. Acta Ecologica Sinica, 36(8): 2151-2163. (in Chinese)

Wang Changjian, Wang Fei, Zhang Xinlin et al., 2017. Examining the driving factors of energy related carbon emissions using the extended STIRPAT model based on IPAT identity in Xinjiang. Renewable and Sustainable Energy Reviews, 67: 51-61.

Wang Changjian, Zhang Xiaolei, Wang Fei et al., 2015. Decomposition of energy-related carbon emissions in Xinjiang and relative mitigation policy recommendations. Frontiers of Earth Science, 9(1): 65-76.

Wang Hongsheng, Wang Yunxia, Wang Haikun et al., 2014. Mitigating greenhouse gas emissions from China's cities: Case study of Suzhou. Energy Policy, 68: 482-489.

Wang Ping, $\mathrm{Wu}$ Wanshui, Zhu Bangzhu et al., 2013. Examining the impact factors of energy-related $\mathrm{CO}_{2}$ emissions using the STIRPAT model in Guangdong Province, China. Applied Energy, 106: 65-71.

Williams James H, DeBenedictis Andrew, Ghanadan Rebecca et al., 2012. The technology path to deep greenhouse gas emissions cuts by 2050: The pivotal role of electricity. Science, 335(6064): 53-59.

Wu F, Fan L W, Zhou P et al., 2012. Industrial energy efficiency with $\mathrm{CO}_{2}$ emissions in China: A nonparametric analysis. Energy Policy, 49: 164-172.

Xi Fengming, Geng Yong, Chen Xudong et al., 2011. Contributing to local policy making on GHG emission reduction through inventorying and attribution: A case study of Shenyang, China. Energy Policy, 39(10): 5999-6010.

Xiao Renjun, 2013. On the role of Xinjiang in guranteeing China's energy security. Xinjiang Finance and Economics, (1): 52-56. (in Chinese)

Zeng Ning, Ding Yihui, Pan Jiahua et al., 2008. Climate change: The Chinese challenge. Science, 319(5864): $730-731$.

Zhang Bo, Chen G Q, 2014. Methane emissions in China 2007. Renewable and Sustainable Energy Reviews, 30: 886-902.

Zhang Bo, Chen G Q, Li J S et al., 2014. Methane emissions of energy activities in China 1980-2007. Renewable and Sustainable Energy Reviews, 29: 11-21.

Zhang Lei, 2003. Economic developmen and its bearing on $\mathrm{CO}_{2}$ emissions. Acta Geographica Sinica, 58(4): 629-637. (in Chinese)

Zhang Lei, 2006. A changing pattern of regional $\mathrm{CO}_{2}$ emissions in China. Geographical Research, 25(1): 1-9. (in Chinese)

Zhang Lei, Todd Daniel, Xie Hui et al., 2005. $\mathrm{CO}_{2}$ emissions and their bearing on China's economic development: The long view. Journal of Geographical Sciences, 15(1): 61-70.

Zhang Qiang, 2008. Developmental approach and strategy of large-scale grid and off-grid wind power industries in Xinjiang. Resources Science, 30(11): 1677-1683. (in Chinese)

Zhu Qin, Peng Xizhe, Wu Kaiya, 2012. Calculation and decomposition of indirect carbon emissions from residential consumption in China based on the input-output model. Energy Policy, 48: 618-626. 